\section{Diseases of the Skin}

James Marshall, M.D.(LOND.). Pp. viii +944 , illustrated. London: E. \& S. Livingstone. 1960. 845 .

The production of a new large textbook of dermatology by a single author is a considerable feat, especially if it is to be therapeutically up to date at the time of publication. Dr. Marshall has tackled the problem with considerable success and has produced a work which should be useful to both students and general practitioners. He points out in the preface that the basic scope of dermatological practice is much the same all over the world and it is interesting to see that he gives views about the incidence and course of diseases in the coloured and black races as well as in Europeans, a point which is often ignored by many British writers.

The book makes easy reading, being written in a simple style. The author's opinions about treatment are often dogmatic. This should be appreciated by the inexperienced practitioner who requires positive advice about this rather than a list of possible therapeutic weapons. He has managed to keep right up to date and even includes a two-page addenda on the use of oral griseofulvin in mycotic infections. Although compression bandaging is rapidly becoming the accepted method of treating hypostatic eczema and ulceration in the British Isles, the author's advice 'that the best results are obtained if the patient is treated at first in bed ' and that "plastic surgery is sometimes the only way cf dealing with chronic ulceration' suggests that accepted therapy in South Africa lags behind that in the United Kingdom.

There are a large array of black and white photographs drawn from a great many sources. While the majority are of high quality and ably illustrate the text, a few show too little contrast and should be replaced when the next edition is prepared.

Notwithstanding the fact that the nomenclature which the author has adopted is largely that in common use, terminology differs in different areas of the Englishspeaking world. The reader wishing to learn about Besnier's prurigo will find no mention of this name in either the index or the text, and unless he is aware that it is also known as atopic eczema his search may be prolonged or even fruitless. It may be impossible to include all the synonyms for each disease but it is a pity that the usual practice of including the more common ones has been omitted.

In spite of these few criticisms this textbook can be recommended as providing the general reader with a large store of sound information and advice.

\section{Electroencephalography in Anesthesiology}

Albert Fallconer, JR., M.D., M.s.; Reginald G. BICKFoRD, M.B., CH.B., M.R.C.P. Pp. $x+90$ illustrated. Springfield, Illinois: Charles C Thomas. I960.

This little book serves as an introduction to encephalography for the anæsthetist. The greater part of it, describing the electroencephalographic patterns associated with various anæsthetic agents, and with certain pathological conditions, consists of material which has already appeared in Anesthesiology. To this has been added an introductory section, a chapter on instrumentation, and a chapter on servo anxsthesia. Those already familiar with the subject will find many gaps in the references, nothing new, and little attempt to go deeply into the subject. For the novice, it is a useful source of information, for it is clearly written, well illustrated and admirably produced.

\section{Recent Advances in Biochemistry}

T. W. Goodwin, D.sc., F.R.I.c. Pp. vi +301 . London: J. \& A. Churchill. r960. 50s.

Professor Goodwin has, to paraphrase a sentence from his preface, given us some bridges across some of the gaps between the general textbooks and the specialized review articles on biochemistry. Some readers will regret that topics in which they are particularly interested have been left out, but few will criticize Professor Goodwin's treatment of those which he has included.

Chapter 1, 'Electron Transport and Oxidative Phosphorylation ', is a lucid account of the mechanisms by which energy is made available for metabolic processes, and includes a valuable section on the biochemistry of the mitochondrion. An account of the modern ideas on the biocynthetic functions of carbon dioxide (' carbon dioxide fixation') is given in Chapter 2. Chapter 3 deals with the chemistry and biosynthesis of the phospholipids, and Chapters 4 to 7 are devoted to the biosynthesis of the aromatic ring, heterocyclic ring systems, the nucleic acids (and related compounds), and the terpenes and terpenoids. The book concludes (Chapter 8) with a simple but stimulating account of the ideas which are being developed concerning the way in which 'various cellular reactions are maintained in a steady state by self-regulatory mechanisms'. This is an exciting subject which may ultimately impinge on our thinking in pathology and medicine.

Although this book is primarily intended for fairly advanced students and junior research workers in biochemistry, it can be recommended to postgraduate workers in the other medical sciences who need concise and readable information on the topics with which it deals. Apart from Chapters $I$ and 8 which are, in the reviewer's opinion, of especial and general interest, the accounts of steroid, porphyrin and nucleic acid biosynthesis will be particularly useful to the biochemicallyinclined physician.

\section{Antenatal and Postnatal Care}

F. J. BRownE, D.SC., M.D., F.R.C.S.ED., F.R.C.O.G.; J. C. MCClure Browne, B.SC., M.B., F.R.C.S.ED., F.R.C.o.g. Pp. viii +435 , illustrated. London: J. \& A. Churchill Ltd. I $960.45 s$.

Professor F. J. Browne and his son are to be congratulated on this latest edition of their book, which has long since achieved the status of an obstetric classic. Whilst preserving its original form, so well known to all obstetricians in this country, it has been revised throughout and new sections have been added on Acute Oliguric Renal Failure, Air Travel, and Intestinal Parasites. Of particular excellence are the chapters on Maturity and Postmaturity, Congenital Malformations and their Inheritance, and the Toxæmias of Pregnancy. The authors write with a clear, lucid style which is eminently readable, and the reproduction and format are first class.

There are a few lapses from established practice, in that cauterization appears to be recommended for cervicitis during pregnancy, whilst ante-partum hæmorrhage is defined as genital tract bleeding occurring between the 2oth week of pregnancy and the onset of labour. 'The word 'cannula', whenever it is used, is wrongly spelt, but these are minor defects compared to the general accuracy of the text throughout the book.

In view of the detailed descriptions of all aspects of antenatal care, together with the lists of references for further reading, it can be recommended as a book essential for students working for their qualifying and higher examinations, and advisable for obstetricians wishing to keep their knowledge and libraries up to date. 